\title{
tRNA cleavage is a conserved response to oxidative stress in eukaryotes
}

\author{
DEBRAH M. THOMPSON, ${ }^{1,2}$ CHENG LU, ${ }^{3}$ PAMELA J. GREEN, ${ }^{3}$ and ROY PARKER ${ }^{1,2}$ \\ ${ }^{1}$ Department of Molecular and Cellular Biology, University of Arizona, Tucson, Arizona 85721, USA \\ ${ }^{2}$ Howard Hughes Medical Institute, University of Arizona, Tucson, Arizona 85721, USA \\ ${ }^{3}$ Delaware Biotechnology Institute, University of Delaware, Newark, Delaware 19711, USA
}

\begin{abstract}
Recent results have identified a diversity of small RNAs in a wide range of organisms. In this work, we demonstrate that Saccharomyces cerevisiae contains a small RNA population consisting primarily of tRNA halves and rRNA fragments. Both 5' and 3 ' fragments of tRNAs are detectable by Northern blot analysis, suggesting a process of endonucleolytic cleavage. tRNA and rRNA fragment production in yeast is most pronounced during oxidative stress conditions, especially during entry into stationary phase. Similar tRNA fragments are also observed in human cell lines and in plants during oxidative stress. These results demonstrate that tRNA cleavage is a conserved aspect of the response to oxidative stress.
\end{abstract}

Keywords: tRNA cleavage; oxidative stress; small RNAs

\section{INTRODUCTION}

Eukaryotic cells contain robust mechanisms to respond to and protect them from stress conditions. Stress conditions stimulate the activation of responses that can include neutralization of the stress, pausing of the cell cycle, alterations in translation, and repair of damage. In extreme cases, when the damage is too great for cellular survival, the response to stress involves apoptotic or necrotic (death) pathways. An important component of stress responses involves controlling RNA metabolism, which often involves a decrease in general translation and preferential translation of mRNAs involved in stress responses (for review, see Holcik and Sonenberg 2005).

tRNAs are a fundamental component of the translation machinery and can also play roles in modulating cell proliferation and stress responses. For example, overexpression of initiator tRNAs contributes to cellular transformation (Marshall et al. 2008). Additionally, during amino acid starvation, uncharged tRNAs function as signaling molecules to activate the kinase Gcn2, which then modulates the response to amino acid starvation (Wek et al. 1995). tRNA production can also be regulated in

Reprint requests to: Roy Parker, Department of Molecular and Cellular Biology, University of Arizona, Tucson, AZ 85721, USA, or Howard Hughes Medical Institute, University of Arizona, Tucson, Arizona 85721, USA; e-mail: rrparker@email.arizona.edu; fax: (520) 621-4524.

Article published online ahead of print. Article and publication date are athttp://www.rnajournal.org/cgi/doi/10.1261/rna.1232808. response to developmental cues (Hentzen et al. 1981), although the mechanisms for down-regulation of tRNAs remain obscure. Recently, half-tRNA molecules have been detected in Tetrahymena and Aspergillus following amino acid starvation (Lee and Collins 2005; Jochl et al. 2008). Such tRNA fragments are intriguing, since tRNA degradation products have been observed in the urine of cancer patients, with levels roughly correlated to the tumor burden (Borek et al. 1977; Speer et al. 1979). However, the mechanisms to generate these tRNA fragments, and their biological significance, are completely unknown.

Over the last decade, it has become increasingly clear that a diversity of small RNA molecules contributes to the control of eukaryotic gene expression. To determine if there are important small RNAs in Saccharomyces cerevisiae, we identified and cloned a small RNA population that primarily consisted of tRNA and rRNA fragments. For tRNAs, both $5^{\prime}$ and $3^{\prime}$ half-molecules were detectable by Northern blot analysis, suggesting a process of endonucleolytic cleavage. This cleavage does not appear to be a mechanism for quality control of misprocessed tRNAs, as it does not increase in several mutant strains with defects in tRNA processing. Instead, we demonstrate that production of these fragments increases during various stress conditions in yeast, most notably oxidative stress. Further work using Arabidopsis and human cell lines indicated that endonucleolytic cleavage of tRNAs is a widely conserved response to oxidative stress in eukaryotes. 


\section{RESULTS}

\section{Yeast has a small RNA population that includes tRNA and rRNA fragments}

The diverse roles of small RNAs prompted us to examine whether the budding yeast $S$. cerevisiae has a small RNA population, even though $S$. cerevisiae lacks the canonical miRNA machinery. To survey small RNAs in yeast, we radiolabeled total yeast RNA at the $3^{\prime}$ end using pCp and examined the RNA on a polyacrylamide gel, revealing that yeast contains a population of RNAs sized at $\sim 40$ nucleotides (nt) (Fig. 1A).

To identify these RNA species, we generated a library from yeast RNAs of between 20 and $70 \mathrm{nt}$ and identified 82 clones from this library by sequencing. The clones (detailed in Supplemental Table 1) included tRNA halves or pieces (30 clones) as well as pieces of rRNAs ( 50 clones, primarily at the $3^{\prime}$ end of the 25s rRNA, Fig. 2A) and snRNA processing fragments (2 clones). The sequenced tRNA fragments are from 10 different tRNAs, include both $5^{\prime}$ and $3^{\prime}$ tRNA pieces, and are derived from tRNAs with and without introns. The $3^{\prime}$ tRNA fragments were identified with and without CCA ends. The ends of many of the tRNA fragments are within the anticodon loop, suggesting that this is a site of endonucleolytic cleavage.

Additional experiments argue that these tRNA pieces are the result of an endonucleolytic cleavage and do not arise from exonucleolytic digestion. First, Northern blot analysis using $5^{\prime}$ or $3^{\prime}$ tRNA-specific probes shows the accumulation of both $5^{\prime}$ and $3^{\prime}$ halves of all tRNAs tested-including those for $\mathrm{tRNA}_{\mathrm{GTC}}^{\mathrm{Asp}}, \mathrm{tRNA}_{\mathrm{TCT}}^{\mathrm{Arg}}, \mathrm{tRNA}_{\mathrm{TTC}}^{\mathrm{Glu}}$,

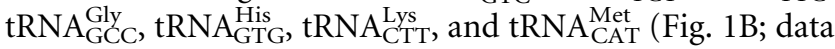
not shown). However, no tRNA fragments were observed by Northern blot analysis using probes for two mitochondrial tRNAs (tRNA $A_{G U G}^{\mathrm{His}}$ and $\mathrm{tRNA}_{\mathrm{ACG}}^{\mathrm{Arg}}$ ), suggesting that this cleavage is limited to cytosolic tRNAs (data not shown). Second, we observed tRNA halves in yeast strains lacking key components of the major known cytoplasmic and nuclear exonucleolytic decay pathways, including $\operatorname{rrp} 6 \Delta$, $\operatorname{trf} 4 \Delta$, $x r n 1 \Delta$, ski2 $\Delta$, and ski7s strains (Fig. 1D). Third, the sizes of the $5^{\prime}$ and $3^{\prime}$ tRNA fragments observed on Northern blots are consistent with being formed by bisection of the full-length tRNA (see estimation in Fig. 1C). These observations, and the sequence data, suggest that yeast tRNAs undergo an endonucleolytic cleavage, which occurs in or near the anticodon loop. It should be noted that the presence of tRNA pieces smaller than halfmolecules in the library clones, and the heterogeneity of the tRNA fragments observed on Northern blots, suggest that some exonucleolytic trimming may follow an initial cleavage.

\section{tRNA cleavage is not a function of quality control}

One possible function of endonucleolytic tRNA cleavage might be to degrade unprocessed, mismodified, or
A

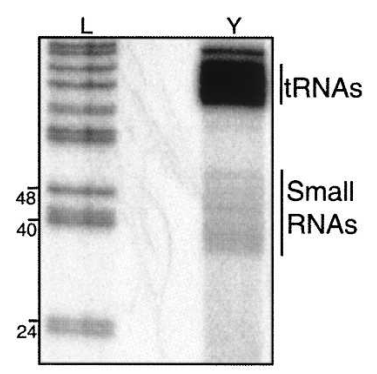

B

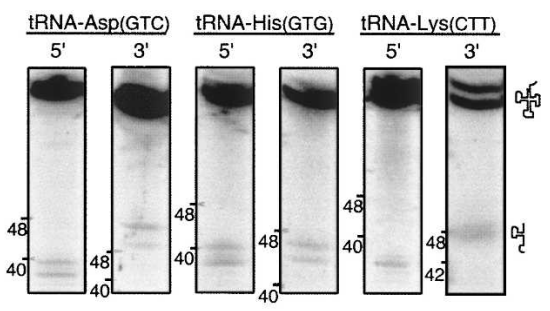

C

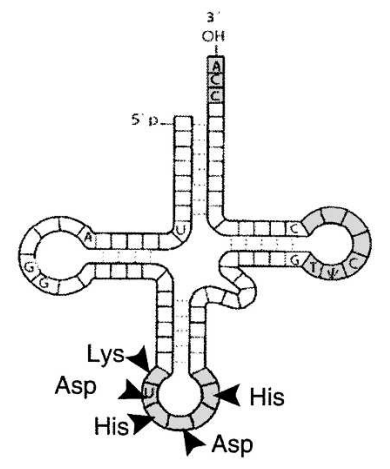

D

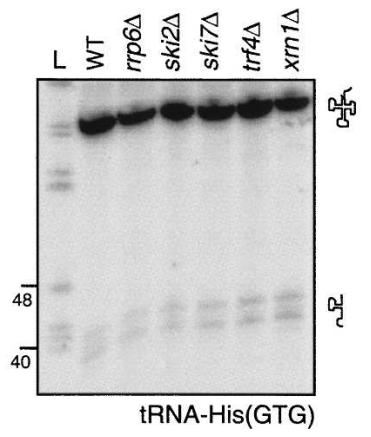

FIGURE 1. The Saccharomyces cerevisiae small RNA population includes tRNA pieces. $(A)$ Total yeast RNA (Y) $3^{\prime}$-end-labeled with $\left[{ }^{32} \mathrm{P}\right]-\mathrm{pCp}$ separated on a $20 \%$ polyacrylamide gel. The small RNA population is indicated. $(B) 5^{\prime}$ - and $3^{\prime}$-specific tRNA probes identify discrete bands on Northern blots. tRNA glyphs indicate full-length and fragment species. $(C)$ Estimated cleavage sites for tRNAs shown in $B$ are indicated. $(D)$ tRNA fragmentation does not increase in strains defective for exonucleolytic decay. The indicated strains and WT control were grown to mid-log phase and harvested for RNA analysis. $5^{\prime}$-tRNA ${ }_{\text {GTG }}^{\text {His }}$ probe. (L) $\varphi$ X174/Hinf 1 ladder. Ladder sizes are indicated in nucleotides. All experiments were repeated at least three times; representative blots are shown. 
A

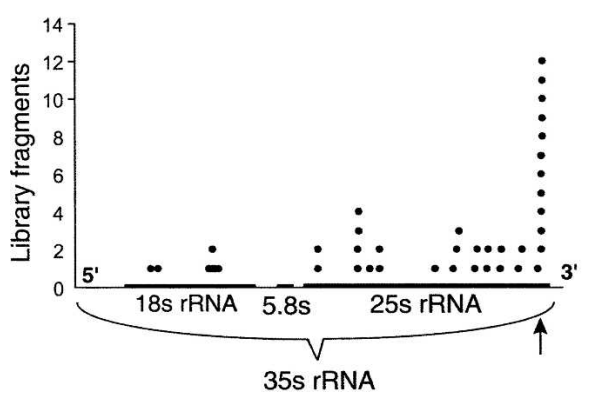

B

Oxidative Stress

C

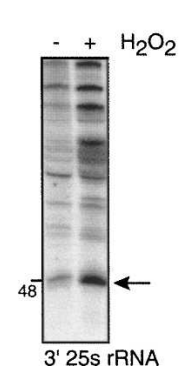

Stationary Phase

Days

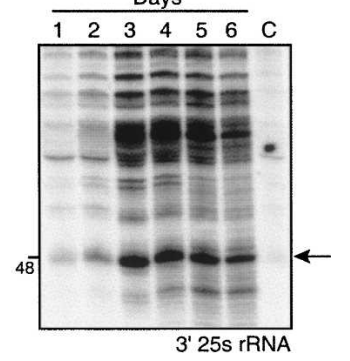

FIGURE 2. rRNA cleavage increases in response to oxidative stress. (A) Location of rRNA fragments from the small-RNA library mapped onto the $35 \mathrm{~s}$ rRNA sequence, with component $5.8 \mathrm{~s}, 18 \mathrm{~s}$, and $25 \mathrm{~s}$ rRNAs indicated. (B) rRNA fragments increase in response to oxidative stress from $\mathrm{H}_{2} \mathrm{O}_{2}$ exposure. 3' $25 \mathrm{~s}$ rRNA probe. (C) rRNA fragments increase during entry into stationary phase; samples collected over $6 \mathrm{~d}$ are compared to a sample from cells in mid-log phase ("C"), to highlight the increase in cleavage. 3' 25s rRNA probe. Arrow indicates the $3^{\prime}$ rRNA fragment discussed in the text. Ladder sizes are indicated in nucleotides. All experiments were repeated at least three times; representative blots are shown.

uncharged tRNAs. If defective tRNAs are subjected to endonucleolytic cleavage, then higher levels of tRNA fragment would be expected in strains with tRNA processing defects. To test this possibility, we examined tRNA fragment levels in three mutant strains in which tRNAs are defective for various reasons: $c c a 1-1$, which has a temperature-sensitive mutation of the enzyme that adds the $3^{\prime}$ CCA sequence to tRNAs (Aebi et al. 1990), hts1.1, which carries a temperature-sensitive mutation of a histidine tRNA synthetase and is defective for tRNA charging at the nonpermissive temperature (Chiu et al. 1992), and trm8s, trm82 , which lacks $\mathrm{m}^{7} \mathrm{G}_{46}$ methyltransferase activity, resulting in a pool of mismodified tRNAs (Alexandrov et al. 2005). None of these mutant strains showed a significant increase in tRNA fragment level as compared to wild-type strains (Fig. 3A-C). These results argue that tRNA cleavage is not a general mechanism for quality control of nonfunctional tRNAs. This interpretation is consistent with recent results showing that mismodified tRNAs are primarily substrates for $5^{\prime}$ to $3^{\prime}$ degradation (Chernyakov et al. 2008; Copela et al. 2008).

\section{tRNA and rRNA cleavages increase during oxidative stress conditions in yeast}

An alternative possibility is that tRNA and/or rRNA cleavage might occur as part of a stress response. This is suggested by earlier work showing that amino acid starvation can promote endonucleolytic cleavage of tRNAs in Tetrahymena (Lee and Collins 2005). To test if tRNA cleavage in yeast is increased by stress, we compared the levels of full-length tRNA and tRNA fragments under a variety of stress conditions.

We observed that many, but not all, stress conditions resulted in increased levels of tRNA fragments (Fig. 4). Yeast subjected to either heat shock (Fig. 4A), methionine starvation (Fig. 4B), nitrogen starvation (Fig. 4F), oxidative stress (Fig. 5A), or approaching stationary phase (Fig. 4C) all showed an increase in fragment levels. Most notably, in

A

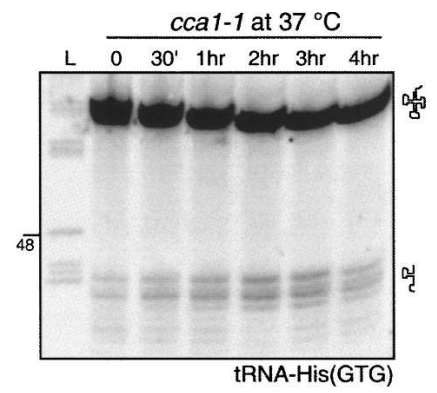

B

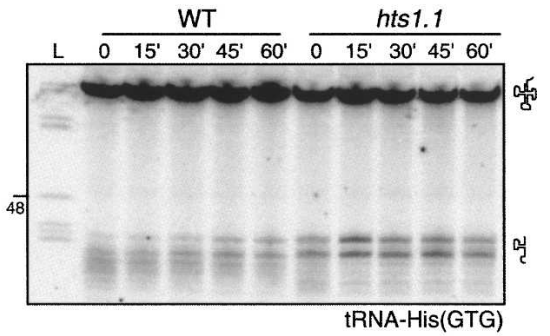

C

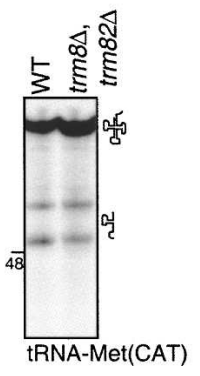

FIGURE 3. tRNA cleavage is not a quality control process. (A) The ccal-1 strain after growth at the nonpermissive temperature $\left(37^{\circ} \mathrm{C}\right)$ for the indicated times. $5^{\prime}$-tRNA $\mathrm{HTT}_{\mathrm{GT}}^{\mathrm{His}}$ probe. (B) hts1.1 cells and control cells grown at the nonpermissive temperature $\left(39^{\circ} \mathrm{C}\right)$ for the indicated times. yRP841 is the WT control strain. $5^{\prime}$-tRNA GTG $_{\text {Gis }}^{\text {Hisobe. }}$ (C) trm $8 \Delta$, trm $82 \Delta$ cells and WT control, grown in glycerol at $37^{\circ} \mathrm{C}$ for $4 \mathrm{~h}$. $3^{\prime}$-tRNA $\mathrm{CAT}$ probe. tRNA glyphs indicate full-length and fragment species. (L) $\varphi \mathrm{X} 174 /$ Hinf 1 ladder. Ladder sizes are indicated in nucleotides. Experiments was repeated at least three times; representative blots are shown. 
cells nearing stationary phase, the levels of tRNA fragment are similar to the levels of full-length mature tRNA (Fig. $4 \mathrm{C}$; data not shown). Moreover, in all cases, the response to stress was not specific to individual tRNAs, as all tRNAs tested showed a similar response-although the magnitude of cleavage may differ between individual tRNAs (see below).

In contrast, no significant increase in tRNA fragment levels was observed during amino acid starvation (other than methionine) (Fig. 4B), during glucose starvation (Fig. 4E), or following exposure to UV light (Fig. 4D)—all conditions under which translation is decreased (see Holcik and Sonenberg 2005). The failure of these stress stimuli to increase tRNA fragment levels indicates that cleavage is not a general consequence of all stresses or an effect of a decrease in translation rates.

To determine whether rRNAs might undergo similar cleavage events during stress, we performed Northern blot analysis on stressed samples using a probe complementary to the $3^{\prime}$ end of the 25s rRNA. This probe corresponded to the most commonly observed rRNA fragment from our library (Fig. 2A, arrow). We observed that the level of this rRNA fragment, as well as other rRNA fragments, increases during exposure to $\mathrm{H}_{2} \mathrm{O}_{2}$ (Fig. 2B, arrow) and during entry into stationary phase (Fig. 2C, arrow). This indicates that stress-induced cleavage of RNAs is not restricted to tRNAs, but also involves other RNA species. Moreover, the generation of multiple rRNA fragments suggests that either the nuclease(s) responsible for rRNA fragmentation has multiple target sites or that there is substantial exonucleolytic degradation of an initial rRNA fragment.

The stress conditions that increased yeast tRNA cleavage all have links to oxidative stress, especially $\mathrm{H}_{2} \mathrm{O}_{2}$ treatment and entry into stationary phase. As yeast approach stationary phase, a large increase in cellular reactive oxygen species occurs, commensurate with induction of apoptosis (Jakubowski et al. 2000). Heat shock has also been shown to induce oxidative stress (Davidson et al. 1996; MedinaSilva et al. 2006). Methionine starvation is less concretely linked with oxidative stress, but potentially could lead to a decrease in glutathione, a key antioxidant (Thomas and Surdin-Kerjan 1997). We conclude that tRNA cleavage in yeast occurs in response to specific stresses, most notably oxidative stress.

\section{tRNA cleavage in response to oxidative stress is conserved in plants and mammals}

To determine whether tRNA cleavage occurs in more complex eukaryotes during oxidative stress, we first exposed Arabidopsis seedlings to $\mathrm{H}_{2} \mathrm{O}_{2}$ to trigger oxidative damage. Similar to the results in yeast, we observed an increase in tRNA fragments during oxidative stress (Fig. 5B). Interestingly, we also observed that the amount of cleavage increased in flowers compared to seedlings (Fig. 6A), and the amount of tRNA fragment differed for individual tRNAs (Fig. 6B). These results indicate that oxidative stress also induces endonucleolytic cleavage of tRNAs in plants.

To examine whether tRNA cleavage also occurs in mammalian cells in response to oxidative stress, we exposed two human cell lines to $\mathrm{H}_{2} \mathrm{O}_{2}$. Both the HeLa and ARPE-19 human cell lines displayed an increase in tRNA fragment level during $\mathrm{H}_{2} \mathrm{O}_{2}$ stress as compared to unstressed control cells (Fig. 5C; data not shown). Thus, oxidative stress triggers endonucleolytic cleavage of tRNAs in mammalian cells.

Two observations indicate that tRNA cleavage in mammalian cells is not a general feature of apoptosis, which can be induced by oxidative stress (Wang et al. 1998). First,

A

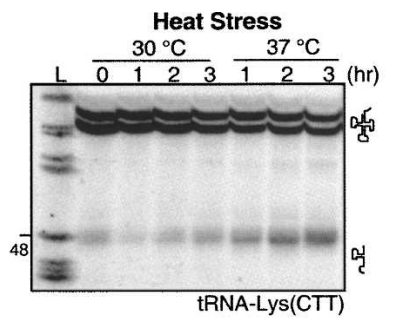

Amino Acid Starvation

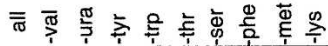

B

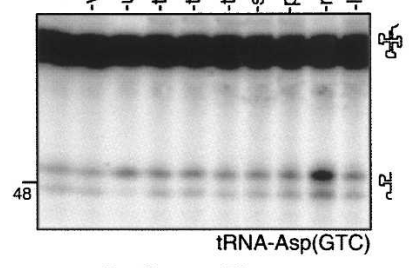

Stationary Phase

C

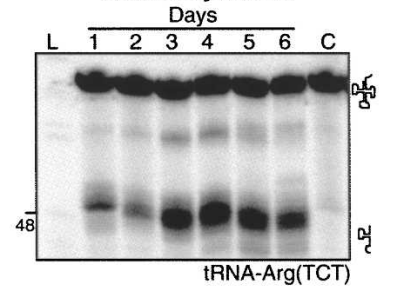

UV Stress

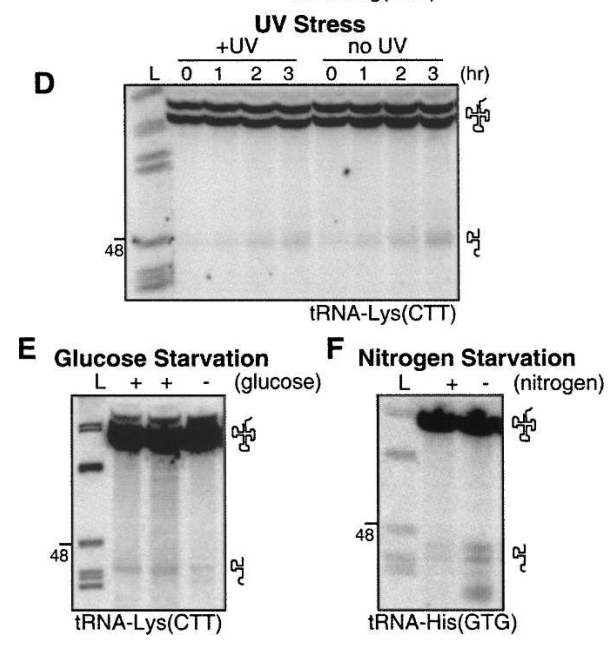

FIGURE 4. (Legend on next page) 
tRNA fragment production peaks after $4 \mathrm{~h}$ of $\mathrm{H}_{2} \mathrm{O}_{2}$ treatment, before visible signs of cell death (i.e., cells rounding up and detaching, which occurs between 10 and $12 \mathrm{~h}$ ), and before the loss of full-length tRNA (Fig. 7A). Second, induction of apoptosis by caffeine, $\alpha$-Fas, or staurosporine treatments (Mao et al. 2004; Lincoln et al. 2006; Bode and Dong 2007) did not enhance tRNA cleavage (Fig. 7B-D). We interpret these observations to indicate that tRNA cleavage in mammalian cells is not generally induced by apoptosis but instead is a response to oxidative stress.

Taken together, these results indicate that oxidative stress triggers tRNA cleavage in yeast, plants, and mammalian cells and is a conserved feature of the cellular response to oxidative stress.

\section{DISCUSSION}

Our results demonstrate that endonucleolytic cleavage of tRNAs is a conserved response to oxidative stress. The critical observation is that $5^{\prime}$ and $3^{\prime}$ tRNA fragments are observed in yeast, plants, and mammalian cells during oxidative stress (Fig. 5). Similar tRNA cleavages have been previously described in other systems. In Tetrahymena, tRNA fragments were observed during amino acid starvation (Lee and Collins 2005), and Haiser et al. (2008) have demonstrated developmental-specific cleavage of tRNAs in the bacterium Streptomyces coelicolor. Recent data from large-scale small-RNA sequencing studies have also identified cleaved tRNAs in human cells (Kawaji et al. 2008) and in Aspergillus (Jochl et al. 2008). In most of these cases, the predicted site of tRNA cleavage is in the anticodon loop, which could be due to the specificity of the relevant nuclease or simply because this region of the tRNA is the most exposed to a nonspecific nuclease. Therefore, a conserved process of stress-induced tRNA cleavage exists in eukaryotes, possibly extending to prokaryotes.

FIGURE 4. Stress conditions induce tRNA cleavage in yeast. (A) Heat stress leads to an increase in tRNA fragment level. WT yeast were harvested at the indicated times after growth at $30^{\circ} \mathrm{C}$ or $37^{\circ} \mathrm{C} .3^{\prime}-$ tRNA LTS $_{\text {LS }}$ probe. $(B)$ tRNA fragment production during amino acid starvation. Cells were collected after $2 \mathrm{~h}$ of starvation for the indicated amino acid. 3'-tRNA Asp probe. $(C)$ Stationary phase entry coincides with a dramatic increase in tRNA fragment. Samples collected over $6 \mathrm{~d}$ are compared to a sample from cells in mid-log phase ("C"), to highlight the increase in cleavage. $3^{\prime}$-tRNA Arg probe. (D) UV exposure does not significantly increase tRNA cleavage in yeast. Yeast treated with 0 or $50 \mathrm{~J} / \mathrm{m}^{2}$ UV were harvested at the indicated times. $3^{\prime}$ tRNA Lys probe. (E) Glucose stress does not significantly increase tRNA fragment production in yeast. WT yeast were grown to mid-log in YEPD, then shifted to YEPD (lane 2), SC medium with glucose (lane 3), or SC medium without glucose (lane 4), and collected after 4 h. $3^{\prime}$-tRNA LCTT probe. $(F)$ Nitrogen starvation increases tRNA fragment production. Yeast cells were grown in media with or without a nitrogen source for $4 \mathrm{~h}$. $3^{\prime}$-tRNA GTT $_{\text {His }}$ probe. tRNA glyphs indicate full-length and fragment species. (L) $\varphi$ X174/Hinf 1 ladder. Ladder sizes are indicated in nucleotides. All experiments were repeated at least three times; representative blots are shown.

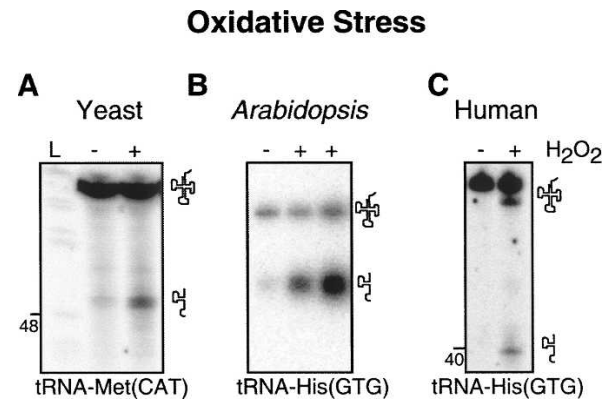

FIGURE 5. Oxidative stress increases tRNA fragment production in yeast, Arabidopsis, and mammalian cells. $(A)$ WT yeast were exposed to 0 or $0.4 \mathrm{mM} \mathrm{H}_{2} \mathrm{O}_{2}$ for $200 \mathrm{~min}$. 3' -tRNA ${ }_{\mathrm{CAT}}^{\mathrm{Met}}$ probe. (B) Two-weekold Arabidopsis seedlings were treated with 0 or $10 \mathrm{mM} \mathrm{H}_{2} \mathrm{O}_{2}$ for 2 or 4 h. 5'-tRNA GTG $^{\text {His }}$ probe. (C) Subconfluent human HeLa cells were treated with 0 or $5 \mathrm{mM} \mathrm{H} \mathrm{H}_{2}$ for $4 \mathrm{~h}$. $3^{\prime}$-tRNA $\mathrm{O}_{\mathrm{GTG}}^{\mathrm{His}}$ probe. tRNA glyphs indicate full-length and fragment species. (L) $\varphi \mathrm{X} 174 / \mathrm{Hinf} 1$ ladder. Ladder sizes are indicated in nucleotides. All experiments were repeated at least three times; representative blots are shown.

We also observe some tRNA cleavage in yeast cells in the absence of any applied stress (Figs. 1, 5). This suggests that either the nuclease cleaving tRNAs is constitutively active at a low level and has its activity enhanced by stress or that a subpopulation of cells in a nonstressed culture is exposed to some type of stress.

An unresolved issue is the identity of the nuclease that cleaves tRNAs and the mechanism by which stress enhances tRNA cleavage. The fact that we also observe enhanced rRNA fragmentation during oxidative stress (Fig. 2) suggests that the nuclease(s) activated during oxidative stress are not specific to tRNAs. One possibility is that during some stress responses, most notably oxidative stress, the engulfment of cytosolic regions into the vacuole by autophagy would expose tRNAs and rRNAs to general nucleases known to be present in the vacuole (Jones et al. 1982). However, this possibility seems unlikely, since yeast strains defective in autophagy show no alteration in the production of tRNA fragments and only a partial effect on rRNA fragmentation (data not shown). Given this observation, we hypothesize that the two most likely possibilities for enhanced tRNA and rRNA cleavage during stress are activation of a general cytosolic nuclease or stress-induced cytosolic release of vacuolar nucleases.

\section{Possible functions of tRNA cleavage}

An intriguing issue is whether tRNA cleavage has any biological function. In one model, tRNAs would be cleaved in order to reduce their functional levels during cellular stress, which might then contribute to translational repression. This would be analogous to previous work showing that cytotoxic tRNases, such as colicins, promote nearly complete cleavage of target tRNAs, resulting in translational inhibition (Ogawa et al. 1999; Tomita et al. 2000). Similarly, stress-related tRNA cleavage in Aspergillus correlates 
A

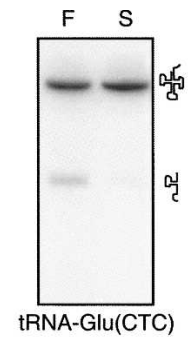

B

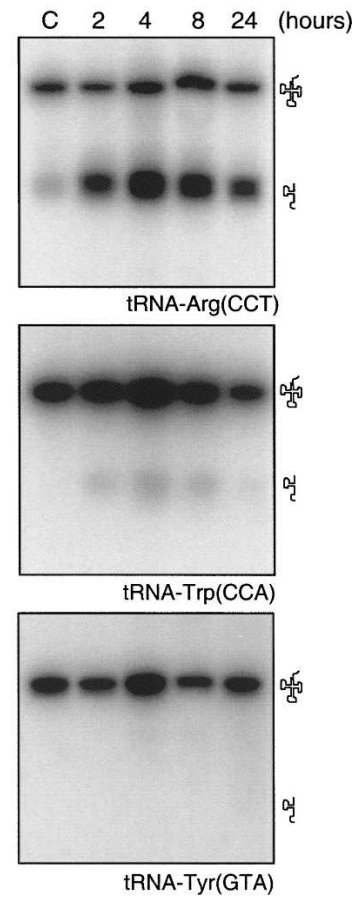

FIGURE 6. Additional examples of tRNA cleavage in Arabidopsis. (A) tRNA cleavage shows a tissue-specific pattern in plants, and accumulates at a higher level in flowers $(\mathrm{F})$ than in seedlings $(\mathrm{S}) .5^{\prime}$-tRNA ${ }_{\mathrm{CTC}}^{\mathrm{GLU}}$ probe. (B) $\mathrm{H}_{2} \mathrm{O}_{2}$-induced cleavage differs among tRNAs. Two-weekold seedlings treated with $0(\mathrm{C})$ or $10 \mathrm{mM} \mathrm{H}_{2} \mathrm{O}_{2}$ for the indicated times were analyzed using the indicated probes. tRNA glyphs indicate full-length and fragment species.

with reductions in full-length tRNA levels and has been hypothesized to inhibit protein synthesis (Jochl et al. 2008). However, in our experiments, enhanced tRNA cleavage during stationary phase or $\mathrm{H}_{2} \mathrm{O}_{2}$ treatment does not significantly reduce the pool of mature yeast tRNAs (Figs. $4 \mathrm{C}, 5 \mathrm{~A}$ ). Moreover, in human cells undergoing oxidative stress, we did not observe loss of full-length tRNAs until after fragment levels had peaked (Fig. 7A). These results suggest that activation of tRNA cleavage by oxidative stress does not generally reduce the levels of mature tRNAs, and therefore may have additional functions. It should also be noted that the activation of nucleases during stress may target other functional RNAs, even mRNAs, that we have yet to identify.

In an alternative model, the tRNA or other RNA fragments produced during oxidative stress could themselves have a function. This could include a role as a signal transducer during oxidative stress, or tRNA fragments may potentially interact with the translation machinery in an inhibitory manner.

In a final model, tRNAs and other RNAs damaged by oxidative stress might be cleaved as part of a quality control process. This possibility is based on the observations that some aberrant tRNAs are degraded (Vanacova et al. 2005; Alexandrov et al. 2006; Chernyakov et al. 2008; Copela et al. 2008). However, we consider this possibility unlikely, since we observed that three strains with different tRNA processing defects did not show either a significant increase in tRNA cleavage compared to controls or a decrease in full-length tRNA (Fig. 2), both of which might be expected if tRNA cleavage is a quality control mechanism. Moreover, we did not observe an increase in tRNA fragments when cells were exposed to UV light (Fig. 4D), which would be expected to induce some tRNA damage.

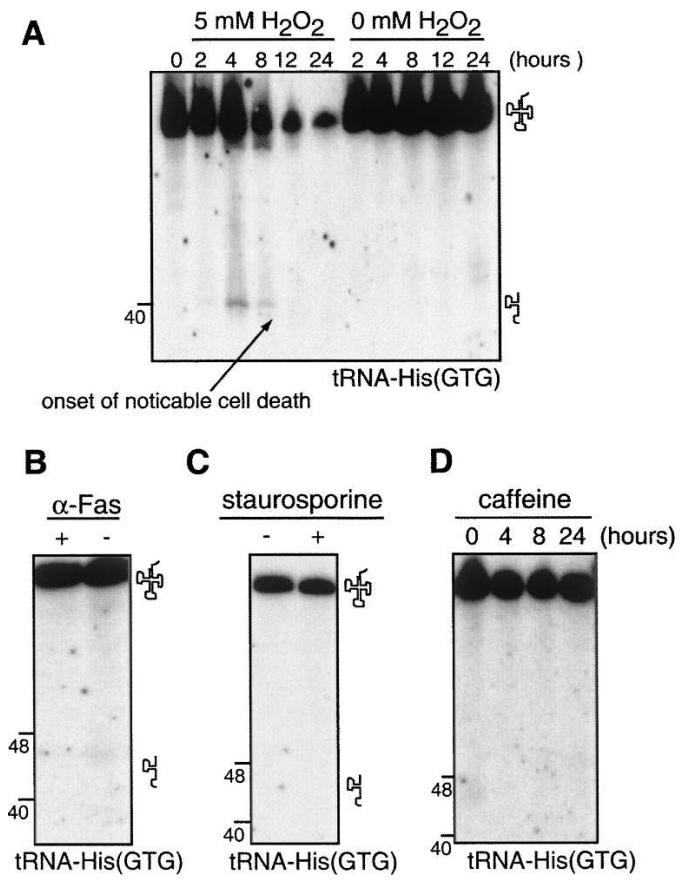

FIGURE 7. tRNA cleavage in mammalian cells is not a general response to all apoptotic inducers. (A) HeLa cells were treated with $5 \mathrm{mM} \mathrm{H}_{2} \mathrm{O}_{2}$ or mock-treated for the indicated times. Arrow indicates when cells were first observed rounding up and detaching. $3^{\prime}-$ tRNA $A_{\mathrm{GTG}}^{\mathrm{His}}$ probe. $(B-D)$ ARPE-19 cells at subconfluence were used for these experiments. In $B$, cells were exposed to the apoptotic inducer $\alpha$-FAS $(1 \mu \mathrm{g} / \mathrm{mL})$ or mock-stressed for $72 \mathrm{~h} .3^{\prime}$-tRNA $\mathrm{GTG}_{\mathrm{GTG}}^{\mathrm{His}}$ probe. In $C$, cells were exposed to the apoptotic inducer staurosporine in DMSO $(1 \mu \mathrm{M})$ or DMSO alone for 4 h. $3^{\prime}$-tRNA $\mathrm{GTG}_{\mathrm{GT}}^{\mathrm{His}}$ probe. For $D$, cells were treated with $16 \mathrm{mM}$ caffeine for the indicated times. $3^{\prime}$ tRNA $\mathrm{GTG}_{\mathrm{GT}}^{\mathrm{Hi}}$ probe. tRNA glyphs indicate full-length and fragment species. (L) $\varphi \mathrm{X} 174 /$ Hinf 1 ladder. Ladder sizes are indicated in nucleotides. All experiments were repeated at least three times; representative blots are shown. 


\section{tRNAs cleavage may affect tumor progression}

Several observations argue that the process of endonucleolytic cleavage of tRNAs affects human tumorigenesis. The levels of reactive oxygen species increase during tumorigenesis, and cancer cells in general tend to have elevated oxidative stress levels (Schumacker 2006). Moreover, tRNA breakdown products are excreted from tumor tissue in a manner that roughly correlates with cancer progression (Borek et al. 1977; Speer et al. 1979). In addition, the frogderived secreted RNase known as Onconase, currently in clinical trials as an anti-cancer therapeutic (Costanzi et al. 2005), has been shown to enter cells and trigger apoptosis in a manner correlated with tRNA cleavage and translational inhibition (Ardelt et al. 1991; Saxena et al. 2002), although its mechanism of action is thought to be more complex and involve additional roles for the RNase (Iordanov et al. 2000; Abraham et al. 2003). This suggests that a further understanding of the functions and mechanism behind tRNA cleavage might not only reveal their biological significance, but may also provide a useful therapeutic target.

\section{MATERIALS AND METHODS}

\section{Construction of plasmids and yeast strains}

Yeast strains used in this study are listed Table 1. Euroscarf deletion strains (Winzeler et al. 1999) can be obtained from Open Biosystems. BY4741 (Open Biosystems) was routinely used as the wild-type (WT) strain, unless indicated. The hts1.1 strain L2236 was obtained from Gerald Fink (Chiu et al. 1992), and the trm84, trm82A strain AA0249 from Eric Phizicky (Alexandrov et al. 2005). Lianna Hatfield constructed strain yRP889.

\section{Yeast growth and stress conditions}

Yeast were routinely cultured at $30^{\circ} \mathrm{C}$ in yeast extract-peptone (YEP) medium with $2 \%$ glucose (YEPD) or in synthetic complete (SC) medium supplemented with $2 \%$ glucose. "Mid-log phase" in all cases indicates growth to $\mathrm{OD}_{600}=0.3-0.5$. For WT and mutant strains shown in Figure 1, B and D, cells were grown to mid-log phase in YEPD and harvested for RNA analysis.

Amino acid starvation was performed in SC medium lacking the indicated amino acid, supplemented with $2 \%$ glucose. Nitrogenstarvation medium $(0.17 \%$ yeast nitrogen base without amino acids or ammonium sulphate, $2 \%$ glucose) lacked both a nitrogen source and all amino acids. Glucose starvation was performed in YEP medium lacking a carbon source. For nitrogen, amino acid, or glucose starvations, yeast were grown in SC or YEP media supplemented with $2 \%$ glucose to mid-log phase, washed in starvation medium, resuspended in starvation medium, and cultured for a further $2-4 \mathrm{~h}$ (time indicated by experiment in the figure legends).

UV exposure was performed in a Stratalinker (Stratagene). Cells were grown to mid-log phase, then $15 \mathrm{~mL}$ aliquots were moved into $10-\mathrm{cm}^{2}$ petri plates and exposed to $50 \mathrm{~J} / \mathrm{m}^{2} \mathrm{UV}$ or mockexposed. Yeast were harvested immediately or returned to a flask to continue growth. Aliquots were removed at the indicated times for RNA analysis. Heat shock was performed by growing cells to mid-log phase in YEPD medium, harvesting, resuspending them in medium prewarmed to $37^{\circ} \mathrm{C}$, allowing them to continue growth at $37^{\circ} \mathrm{C}$, and harvesting for RNA at the indicated times. The hts1.1 strain (L2236) (Chiu et al. 1992) and the yRP841 WT control strain were grown in SC medium lacking histidine and supplemented with $2 \%$ glucose at $30^{\circ} \mathrm{C}$ until mid-log phase. Cells were shifted to $39^{\circ} \mathrm{C}$ and aliquots were removed for RNA analysis at the indicated times. The ccal-1 strain yRP889 was grown in YEPD at $24^{\circ} \mathrm{C}$ to mid-log phase, then shifted to $37^{\circ} \mathrm{C}$. Aliquots were removed at the indicated times for RNA analysis. trm $8 \Delta$, trm824 (AA0249) (Alexandrov et al. 2005) yeast were grown in YEPD to mid-log phase, washed once in SC medium, and resuspended in SC medium supplemented with $2 \%$ glycerol and prewarmed to $37^{\circ} \mathrm{C}$. Cells were grown at $37^{\circ} \mathrm{C}$ for $4 \mathrm{~h}$, then harvested for RNA analysis.

\section{Apoptosis and stationary phase}

For induction of oxidative stress by $\mathrm{H}_{2} \mathrm{O}_{2}$ exposure, yeast cells were grown to mid-log phase, then $\mathrm{H}_{2} \mathrm{O}_{2}$ (Sigma) was added to a final concentration of $0.4 \mathrm{mM}$ and cells were cultured for a further $200 \mathrm{~min}$. This concentration of $\mathrm{H}_{2} \mathrm{O}_{2}$ has been shown to induce apoptotic markers, reduce survival of cells, and result in TUNELpositive staining in yeast (Madeo et al. 1999; Wissing et al. 2004).

TABLE 1. Yeast strains used in this study

\begin{tabular}{|c|c|c|}
\hline Strain & Genotype & Reference \\
\hline BY4741 & 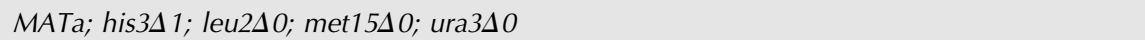 & Winzeler et al. (1999) \\
\hline Y0 1852 & 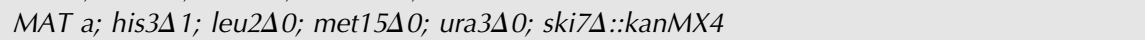 & Winzeler et al. (1999) \\
\hline Y0 5307 & 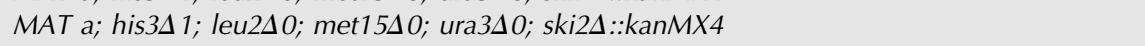 & Winzeler et al. (1999) \\
\hline Y0 4540 & 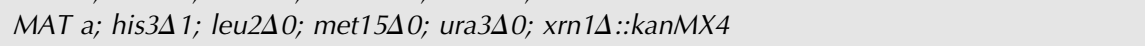 & Winzeler et al. (1999) \\
\hline Y0 1777 & 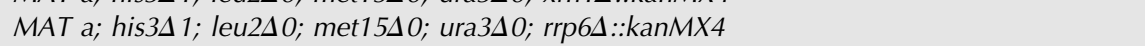 & Winzeler et al. (1999) \\
\hline Y0 6265 & 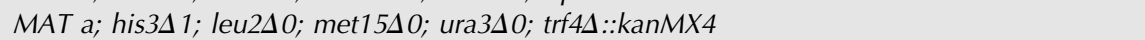 & Winzeler et al. (1999) \\
\hline yRP 841 & MATo; leu2; lys; trp; ura3; cup1::LEU2/PGK1pG/MFA2pG & Hatfield et al. (1996) \\
\hline yRP 889 & MAT a; leu2-3,112; his; trp1; ura3-52; cca1-1; cup1::LEU2/PGK1pG/MFA2pG & This study \\
\hline L2236 & MAT $\alpha ;$ hts1.1; leu2-2; ura3-52 & Chiu et al. (1992) \\
\hline AA0249 & 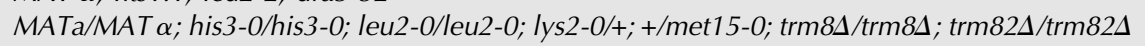 & Alexandrov et al. (2005) \\
\hline
\end{tabular}


For longer-term (stationary phase) growth experiments, cells from an overnight culture were diluted into fresh SC medium with $2 \%$ glucose and grown for $6 \mathrm{~d}$ at $30^{\circ} \mathrm{C}$ without medium change. Aliquots were taken from the culture each day for analysis.

\section{Yeast small-RNA library construction}

The yeast small-RNA library was constructed basically as described ( $\mathrm{Lu}$ et al. 2007), except that the initial RNA isolation included species from 20 to 70 nt. A second library was constructed in a similar manner except that, to include species regardless of $5^{\prime}$ end, the $3^{\prime}$ linker was added, and 5' RACE followed by PCR was performed on the pool of RNAs using the $5^{\prime}$ RACE System for Rapid Amplification of cDNA Ends (Invitrogen). Following PCR amplification and gel isolation of correctly sized library products, a small amount was cloned into TOPO (Invitrogen) or pGEM-T-easy (Promega) vectors. Insert-containing clones were sequenced by Agencourt Bioscience using T3 and Sp6 primers (TA vector) or indicated primers for the TOPO vectors (Lu et al. 2007).

\section{RNA analysis}

Labeling of total RNA with $\left[{ }^{32} \mathrm{P}\right]-\mathrm{pCp}$ was done according to standard methods. RNA extraction and blotting were performed essentially as described (Caponigro et al. 1993). Briefly, 25-50 $\mu \mathrm{g}$ of RNA were routinely loaded onto $12 \%$ or $15 \%$ polyacrylamide gels containing $8 \mathrm{M}$ urea, blotted onto Nytran membrane, detected using $5^{\prime}$-end $\left[\gamma^{-32} \mathrm{P}\right]$-ATP-labeled oligonucleotide probes, and scanned using a PhosphorImager (Typhoon 9410; Amersham Biosciences). Yeast tRNA probe sequences used in this study are:

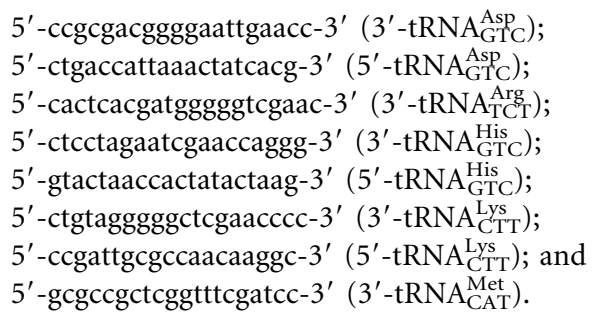

The yeast $3^{\prime} 25$ s rRNA probe $\left(5^{\prime}\right.$-caaaggcttaatctcagcagatcg- $\left.3^{\prime}\right)$ used was designed against the most common rRNA piece found in our library (see Supplemental Table 1). For mammalian RNA isolation, TRIzol (Invitrogen) was used according to package insert instructions. Ten to $50 \mu \mathrm{g}$ of human RNA were run as described above and probed with a $3^{\prime}$-tRNA GTC $_{\text {His }}$ probe $\left(5^{\prime}\right.$ gccgtgactcggattcgaacc- $3^{\prime}$ ).

\section{Mammalian tissue culture}

HeLa cells were a gift of John Bloom (University of Arizona), and ARPE-19 cells were a gift from Priscilla Schafer (University of Arizona). Cells were grown in DMEM (Gibco) supplemented with $10 \%$ fetal bovine serum (HyClone), $2 \mathrm{mM} \mathrm{L-glutamine} \mathrm{(Sigma),}$ $100 \mathrm{U} / \mathrm{mL}$ penicillin, and $100 \mu \mathrm{L} / \mathrm{mL}$ streptomycin (Hyclone), at $37^{\circ} \mathrm{C}$ in a humidified incubator with $5 \% \mathrm{CO}_{2}$. Cells were routinely passaged at subconfluence and fed twice a week. For stress experiments, cells were plated at subconfluency $18-24 \mathrm{~h}$ prior to the experiment, then fed with medium containing stress-inducing substances or a control, as indicated in figure legends. Staurosporine (in DMSO) and caffeine were obtained from Sigma, $\alpha$ Fas was obtained from Roche. Staurosporine was added to a final concentration of $1 \mu \mathrm{M}$, and DMSO alone was used as a control for staurosporine exposure. Caffeine was used at a final concentration of $16 \mathrm{mM}, \mathrm{H}_{2} \mathrm{O}_{2}$ was added to a final concentration of $5 \mathrm{mM}$, and $\alpha$-Fas was added to a final concentration of $1 \mu \mathrm{g} / \mathrm{mL}$.

\section{Plant $\mathrm{H}_{2} \mathrm{O}_{2}$ treatment}

Arabidopsis thaliana ecotype Columbia was used. Plants were grown on Murashige and Skoog (MS) medium containing 1\% sucrose, $1 \times$ Gamborg's vitamins. Seeds were sterilized and stratified for $2 \mathrm{~d}$ at $4^{\circ} \mathrm{C}$, then transferred to a growth chamber at $22^{\circ} \mathrm{C}$ with $16-\mathrm{h} / 8-\mathrm{h}$ light/dark cycles. Two-week-old seedlings were then transferred to a flask with half strength of MS solution and $10 \mathrm{mM} \mathrm{H}_{2} \mathrm{O}_{2}$. Samples were harvested at different time points and quickly frozen in liquid nitrogen. Control plants were mocktreated by half strength of MS solution only. Sequences of probes used for RNA analysis are:

\section{$5^{\prime}$-gagccgagtatcctgaccagctagactacaacgga- $3^{\prime}\left(5^{\prime}\right.$-tRNA $\left.{ }_{\mathrm{CTC}}^{\mathrm{Glu}}\right)$; \\ $5^{\prime}$-aacgtggaattctaaccactaaactacagccac- $3^{\prime}\left(5^{\prime}-\mathrm{tRNA}_{\mathrm{GTG}}^{\mathrm{His}}\right)$; \\ $5^{\prime}$-tacagtcttccgctctaccaactgagctaaggtcgg- $3^{\prime}$ ( $5^{\prime}$-tRNA $\left.{ }_{\mathrm{GTA}}^{\mathrm{Tyr}}\right)$; and $5^{\prime}$-aggaaacagacgctctatccactgagctacaggcgc- $3^{\prime}\left(5^{\prime}-\mathrm{tRNA}_{\mathrm{CC} \mathrm{T}}^{\mathrm{Arg}}\right)$.}

\section{SUPPLEMENTAL DATA}

Supplemental material can be found at http://www.rnajournal.org.

\section{ACKNOWLEDGMENTS}

We are grateful to John Bloom, Gerald Fink, Anita Hopper, Eric Phizicky, and Priscilla Schafer for strains, plasmids, and cell lines. We thank Carolyn Decker for critical review of the manuscript and the members of the Parker laboratory for support and discussions while this work was ongoing. Research for this article was supported by the Howard Hughes Medical Institute or National Science Foundation grants MCB\#0445638 and 0548569 (to P.J.G.).

Received June 14, 2008; accepted June 30, 2008.

\section{REFERENCES}

Abraham, A.T., Lin, J.J., Newton, D.L., Rybak, S., and Hecht, S.M. 2003. RNA cleavage and inhibition of protein synthesis by bleomycin. Chem. Biol. 10: 45-52.

Aebi, M., Kirchner, G., Chen, J.Y., Vijayraghavan, U., Jacobson, A., Martin, N.C., and Abelson, J. 1990. Isolation of a temperaturesensitive mutant with an altered tRNA nucleotidyltransferase and cloning of the gene encoding tRNA nucleotidyltransferase in the yeast Saccharomyces cerevisiae. J. Biol. Chem. 265: 1621616220.

Alexandrov, A., Grayhack, E.J., and Phizicky, E.M. 2005. tRNA m7G methyltransferase Trm8p/Trm82p: Evidence linking activity to a growth phenotype and implicating Trm82p in maintaining levels of active Trm8p. RNA 11: 821-830. 
Alexandrov, A., Chernyakov, I., Gu, W., Hiley, S.L., Hughes, T.R., Grayhack, E.J., and Phizicky, E.M. 2006. Rapid tRNA decay can result from lack of nonessential modifications. Mol. Cell 21: 87-96.

Ardelt, W., Mikulski, S.M., and Shogen, K. 1991. Amino acid sequence of an anti-tumor protein from Rana pipiens oocytes and early embryos. Homology to pancreatic ribonucleases. J. Biol. Chem. 266: 245-251.

Bode, A.M. and Dong, Z. 2007. The enigmatic effects of caffeine in cell cycle and cancer. Cancer Lett. 247: 26-39.

Borek, E., Baliga, B.S., Gehrke, C.W., Kuo, C.W., Belman, S., Troll, W., and Waalkes, T.P. 1977. High turnover rate of transfer RNA in tumor tissue. Cancer Res. 37: 3362-3366.

Caponigro, G., Muhlrad, D., and Parker, R. 1993. A small segment of the MAT $\alpha 1$ transcript promotes mRNA decay in Saccharomyces cerevisiae: A stimulatory role for rare codons. Mol. Cell. Biol. 13: 5141-5148.

Chernyakov, I., Whipple, J.M., Kotelawala, L., Grayhack, E.J., and Phizicky, E.M. 2008. Degradation of several hypomodified mature tRNA species in Saccharomyces cerevisiae is mediated by Met22 and the 5'-3' exonucleases Rat1 and Xrn1. Genes \& Dev. 22: 13691380.

Chiu, M.I., Mason, T.L., and Fink, G.R. 1992. HTS1 encodes both the cytoplasmic and mitochondrial histidyl-tRNA synthetase of Saccharomyces cerevisiae: Mutations alter the specificity of compartmentation. Genetics 132: 987-1001.

Copela, L.A., Fernandez, C.F., Sherrer, R.L., and Wolin, S.L. 2008. Competition between the Rexl exonuclease and the La protein affects both Trf4p-mediated RNA quality control and pre-tRNA maturation. RNA 14: 1214-1227.

Costanzi, J., Sidransky, D., Navon, A., and Goldsweig, H. 2005. Ribonucleases as a novel pro-apoptotic anticancer strategy: Review of the preclinical and clinical data for ranpirnase. Cancer Invest. 23: $643-650$.

Davidson, J.F., Whyte, B., Bissinger, P.H., and Schiestl, R.H. 1996. Oxidative stress is involved in heat-induced cell death in Saccharomyces cerevisiae. Proc. Natl. Acad. Sci. 93: 5116-5121.

Haiser, H.J., Karginov, F.V., Hannon, G.J., and Elliot, M.A. 2008. Developmentally regulated cleavage of tRNAs in the bacterium Streptomyces coelicolor. Nucleic Acids Res. 36: 732-741.

Hatfield, L., Beelman, C.A., Stevens, A., and Parker, R. 1996. Mutations in trans-acting factors affecting mRNA decapping in Saccharomyces cerevisiae. Mol. Cell. Biol. 16: 5830-5838.

Hentzen, D., Chevallier, A., and Garel, J.P. 1981. Differential usage of iso-accepting tRNA ${ }^{\text {Ser }}$ species in silk glands of Bombyx mori. Nature 290: 267-269.

Holcik, M. and Sonenberg, N. 2005. Translational control in stress and apoptosis. Nat. Rev. Mol. Cell Biol. 6: 318-327.

Iordanov, M.S., Ryabinina, O.P., Wong, J., Dinh, T.H., Newton, D.L., Rybak, S.M., and Magun, B.E. 2000. Molecular determinants of apoptosis induced by the cytotoxic ribonuclease onconase: Evidence for cytotoxic mechanisms different from inhibition of protein synthesis. Cancer Res. 60: 1983-1994.

Jakubowski, W., Bilinski, T., and Bartosz, G. 2000. Oxidative stress during aging of stationary cultures of the yeast Saccharomyces cerevisiae. Free Radic. Biol. Med. 28: 659-664.

Jochl, C., Rederstorff, M., Hertel, J., Stadler, P.F., Hofacker, I.L., Schrettl, M., Haas, H., and Huttenhofer, A. 2008. Small ncRNA transcriptome analysis from Aspergillus fumigatus suggests a novel mechanism for regulation of protein synthesis. Nucleic Acids Res. 36: $2677-2689$.

Jones, E.W., Zubenko, G.S., and Parker, R.R. 1982. PEP4 gene function is required for expression of several vacuolar hydrolases in Saccharomyces cerevisiae. Genetics 102: 665-677.

Kawaji, H., Nakamura, M., Takahashi, Y., Sandelin, A., Katayama, S., Fukuda, S., Daub, C.O., Kai, C., Kawai, J., Yasuda, J., et al. 2008. Hidden layers of human small RNAs. BMC Genomics 9: 157.
Lee, S.R. and Collins, K. 2005. Starvation-induced cleavage of the tRNA anticodon loop in Tetrahymena thermophila. J. Biol. Chem. 280: 42744-42749.

Lincoln, J.E., Boling, M., Parikh, A.N., Yeh, Y., Gilchrist, D.G., and Morse, L.S. 2006. Fas signaling induces raft coalescence that is blocked by cholesterol depletion in human RPE cells undergoing apoptosis. Invest. Ophthalmol. Vis. Sci. 47: 2172-2178.

Lu, C., Meyers, B.C., and Green, P.J. 2007. Construction of small RNA cDNA libraries for deep sequencing. Methods 43: 110117.

Madeo, F., Frohlich, E., Ligr, M., Grey, M., Sigrist, S.J., Wolf, D.H., and Frohlich, K.U. 1999. Oxygen stress: A regulator of apoptosis in yeast. J. Cell Biol. 145: 757-767.

Mao, Y.W., Liu, J.P., Xiang, H., and Li, D.W. 2004. Human $\alpha$ A- and $\alpha \mathrm{B}$-crystallins bind to $\mathrm{Bax}$ and $\mathrm{Bcl}-\mathrm{X}(\mathrm{S})$ to sequester their translocation during staurosporine-induced apoptosis. Cell Death Differ. 11: 512-526.

Marshall, L., Kenneth, N.S., and White, R.J. 2008. Elevated. tRNA $\mathrm{Met}_{\mathrm{i}}$ synthesis can drive cell proliferation and oncogenic transformation. Cell 133: 78-89.

Medina-Silva, R., Barros, M.P., Galhardo, R.S., Netto, L.E., Colepicolo, P., and Menck, C.F. 2006. Heat stress promotes mitochondrial instability and oxidative responses in yeast deficient in thiazole biosynthesis. Res. Microbiol. 157: 275-281.

Ogawa, T., Tomita, K., Ueda, T., Watanabe, K., Uozumi, T., and Masaki, H. 1999. A cytotoxic ribonuclease targeting specific transfer RNA anticodons. Science 283: 2097-2100.

Saxena, S.K., Sirdeshmukh, R., Ardelt, W., Mikulski, S.M., Shogen, K., and Youle, R.J. 2002. Entry into cells and selective degradation of tRNAs by a cytotoxic member of the RNase A family. J. Biol. Chem. 277: 15142-15146.

Schumacker, P.T. 2006. Reactive oxygen species in cancer cells: Live by the sword, die by the sword. Cancer Cell 10: 175-176.

Speer, J., Gehrke, C.W., Kuo, K.C., Waalkes, T.P., and Borek, E. 1979. tRNA breakdown products as markers for cancer. Cancer 44: 2120-2123.

Thomas, D. and Surdin-Kerjan, Y. 1997. Metabolism of sulfur amino acids in Saccharomyces cerevisiae. Microbiol. Mol. Biol. Rev. 61: 503-532.

Tomita, K., Ogawa, T., Uozumi, T., Watanabe, K., and Masaki, H. 2000. A cytotoxic ribonuclease which specifically cleaves four isoaccepting arginine tRNAs at their anticodon loops. Proc. Natl. Acad. Sci. 97: 8278-8283.

Vanacova, S., Wolf, J., Martin, G., Blank, D., Dettwiler, S., Friedlein, A., Langen, H., Keith, G., and Keller, W. 2005. A new yeast poly(A) polymerase complex involved in RNA quality control. PLoS Biol. 3: e189. doi: 10.1371/journal.pbio.0030189.

Wang, X., Martindale, J.L., Liu, Y., and Holbrook, N.J. 1998. The cellular response to oxidative stress: Influences of mitogen-activated protein kinase signalling pathways on cell survival. Biochem. J. 333: 291-300.

Wek, S.A., Zhu, S., and Wek, R.C. 1995. The histidyl-tRNA synthetase-related sequence in the eIF-2 $\alpha$ protein kinase GCN2 interacts with tRNA and is required for activation in response to starvation for different amino acids. Mol. Cell. Biol. 15: 44974506.

Winzeler, E.A., Shoemaker, D.D., Astromoff, A., Liang, H., Anderson, K., Andre, B., Bangham, R., Benito, R., Boeke, J.D., Bussey, H., et al. 1999. Functional characterization of the $S$. cerevisiae genome by gene deletion and parallel analysis. Science 285: 901-906.

Wissing, S., Ludovico, P., Herker, E., Buttner, S., Engelhardt, S.M., Decker, T., Link, A., Proksch, A., Rodrigues, F., Corte-Real, M., et al. 2004. An AIF orthologue regulates apoptosis in yeast. J. Cell Biol. 166: 969-974. 

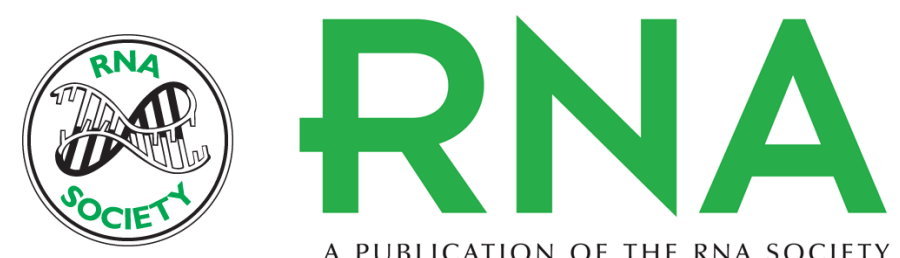

A PUBLICATION OF THE RNA SOCIETY

\section{tRNA cleavage is a conserved response to oxidative stress in eukaryotes}

Debrah M. Thompson, Cheng Lu, Pamela J. Green, et al.

RNA 2008 14: 2095-2103 originally published online August 21, 2008

Access the most recent version at doi:10.1261/rna.1232808

\section{Supplemental http://rnajournal.cshlp.org/content/suppl/2008/08/21/rna.1232808.DC1 \\ Material}

References This article cites 40 articles, 23 of which can be accessed free at: http://rnajournal.cshlp.org/content/14/10/2095.full.html\#ref-list-1

Open Access Freely available online through the RNA Open Access option.

License Freely available online through the open access option.

Email Alerting Receive free email alerts when new articles cite this article - sign up in the box at the Service top right corner of the article or click here. 